\title{
Pretend play, deferred imitation and parent- child interaction in speaking and non-speaking children with autism
}

Karin Strid, Tomas Tjus and Mikael Heimann

\section{Linköping University Post Print}

N.B.: When citing this work, cite the original article.

This is the pre-reviewed version of the following article:

Karin Strid, Tomas Tjus and Mikael Heimann, Pretend play, deferred imitation and parentchild interaction in speaking and non-speaking children with autism, 2013, Scandinavian Journal of Psychology, (54), 1, 26-32.

which has been published in final form at:

http://dx.doi.org/DOI: 10.1111/sjop.12003

Copyright: Wiley-Blackwell

http://eu.wiley.com/WileyCDA/Brand/id-35.html

Postprint available at: Linköping University Electronic Press

http://urn.kb.se/resolve?urn=urn:nbn:se:liu:diva-80617 
Running head: PLAY AND DEFERRED IMITATION IN AUTISM

Pretend play, deferred imitation and parent-child interaction in speaking and non-speaking children with autism

Karin Strid ${ }^{1}$, Mikael Heimann ${ }^{2,3}$, Tomas Tjus ${ }^{1}$

\author{
${ }^{1}$ University of Gothenburg, Sweden \\ ${ }^{2}$ Linköping University, Sweden
}

${ }^{3}$ Swedish Institute of Disability Research 


\begin{abstract}
This study investigates spontaneous pretend play during a parent-child free play observation, and deferred imitation observed in an experimental setting in speaking and nonspeaking children with autism in comparison to children with typical development. Both groups of children with autism showed a reduced level of deferred imitation compared to the typically developing group, but only the non-speaking children with autism spent significantly less time in pretend play compared to children with typical development. Deferred imitation was related to parents' verbal interaction in both groups. An analysis of the parent-child interaction revealed that parents of children with autism used less synchronized comments compared to parents of typically developing children. Parents of the speaking group with autism used more synchronized than unsynchronized comments, while parents of the nonspeaking group used the same amount of synchronized and unsynchronized comments. These findings are discussed in terms of how the developmental level affects behaviour and interaction in autism.
\end{abstract}

Key Words: Autism; pretend play; deferred imitation; parent interaction; recall memory; language level. 
Pretend play, deferred imitation and parent-child interaction in speaking and non-speaking children with autism

Autism is a developmental disorder affecting social interaction, communication and flexibility. There is a huge heterogeneity in this group in terms of level of functioning and language abilities (Wing, 1997). Many children with autism remain non-speaking and there are important differences between the children with autism that develop spoken language and those who do not, and gaining language is an important predictor of positive outcome in children with autism (Gillberg, 1991). In the present study, the participants include both speaking and non-speaking children with autism and they are compared to children with typical development.

The focus of the paper is on pretend play and deferred imitation, and how these areas are related to the parental interaction style and the child's language. Positive relations between pretend play and deferred imitation have been found at several time-points during the second year of life among typically developing infants (Nielsen \& Dissanayake, 2004), and in children with autism at the age of 3-4 years (Toth, Munson, Meltzoff, \& Dawson, 2006). Children's development of pretend play is affected by parents' involvement in play and children show more advanced play behaviour when they are interacting with an adult (Noll \& Harding, 2003; Slade, 1987). How the development of deferred imitation is facilitated by differences in parental interaction style is less investigated, but imitation is known to be affected by the social environment (McEwan, et al., 2007).

\section{Pretend play}

Pretend play, or symbolic play, (the terms are used interchangeably here) occurs when a child is using an object as something else, pretending that the object has properties that it has not, and/or when the child is using imaginary objects (Leslie, 1987). Children with autism 
engage in less pretend play compared to children with other developmental delays and children with typical development (see Jarrold, 2003 for a review). In addition, some studies report spontaneous pretend play to be more affected among children with autism (Jarrold, 2003; Wing, 1997) than elicited/prompted pretend play (Charman \& Baron-Cohen, 1997). The lack of spontaneous pretend play suggests that even if the child has the ability, pretending seems to be less motivating, fun or meaningful for children with an autism diagnosis as compared to typically developing children (Harris, 1989).

\section{Deferred imitation}

Deferred imitation is a nonverbal measure of recall memory that has been used in numerous studies on infants and has revealed remarkable memory abilities in the first year of life (e.g. Barr, Dowden, \& Hayne, 1996). Deferred imitation predicts both early communicative and cognitive development in typically developing children (Heimann, Strid, Smith, Tjus, Ulvund, \& Meltzoff, 2006; Strid, Tjus, Smith, Meltzoff, \& Heimann, 2006). Children with autism seem to be impaired in deferred imitation (Dawson, Meltzoff, Osterling, \& Rinaldi, 1998; Strid, Heimann, Smith, Gillberg, \& Tjus, submitted; Rogers, Young, Cook, Giolzetti, \& Ozonoff, 2008) and two studies (Munson, Faja, Meltzoff, Abbott, \& Dawson, 2008; Toth, et al., 2006) found that deferred imitation measured in young children with autism predicted the rate of acquisition of communication skills in this group.

\section{Parental interaction style}

Differences in the verbal interaction style have been observed between parents of children with autism and parents of children with typical development (Watson, 1998) and between parents of verbal and nonverbal children with autism (Konstantareas, Zajdeman, Homatidis, \& McCabe, 1988). Social interaction involves at least two people. Therefore, if one part of the dyad has a challenging, difficult or unusual response repertoire, as in autism, it may affect the behaviour of the other part of the dyad (see Hedenbro \& Tjus, 2007, for a case 
study of autism). Both parents and teachers of children with autism are reported to control the interaction by using more directives (Kasari, Sigman, Mundy, \& Yirmiya, 1988; Tjus, Heimann, \& Nelson, 2001). Furthermore, parents of children with autism use more unsynchronized comments than parents of typically developing children (Watson, 1998). This kind of interactive style is a possible risk factor for negative language development for both children with typical development and children with developmental delays (Eheart, 1982; Tomasello \& Farrar, 1987), but the use of synchronized comments has yielded a positive impact in children with autism (Green et al., 2010; Siller \& Sigman, 2002), i.e. an increase of conceptual representations (Waxman, 2002).

\section{Pretend play, deferred imitation and parent-child interaction}

Both pretend play and deferred imitation have been suggested to rely on the child's ability of representational thought. Deferred imitation requires that the child can form a representation of a seen action, store that representation in memory, and use it at a later timepoint. In comparison, pretend play depends on a meta-representational ability; to simultaneously hold a real and a pretended representation in mind (Leslie, 1987; Meltzoff, 2004). Thus, the first aim of the present study was to explore the relationship between deferred imitation and pretend play in a group of children with autism (speaking and nonspeaking) compared to a group of typically developing children. A second aim of the present study was to investigate how individual differences in pretend play and deferred imitation are related to the interaction style of the parent during play, since a supportive parental behaviour using synchronized verbalizations i.e. verbal comments within the child's focus of attention are associated with better language skills (Siller \& Sigman, 2008; Tomasello \& Farrar, 1987).

\section{Research Questions}

The present study investigates how children with autism (speaking and/or non-speaking) and children with typical development differ in a) pretend play, b) deferred imitation and c) 
parents' type of comments (synchronized/unsynchronized) in a free play situation The relation between pretend play, deferred imitation and parents' comments was also investigated.

We hypothesised that a) children with autism will engage in less pretend play and show a lower frequency of deferred imitation compared to typically developing children, b) pretend play will be positively related to deferred imitation both in children with autism and typically developing children, c) parents of children with autism will use more unsynchronized comments during play compared to parents of children with typical development, and d) pretend play will be positively related to parents use of synchronized comments both in children with autism and in typically developing children.

\section{Method}

\section{Participants}

Twenty children diagnosed with autism ( 18 boys, mean age $=66.8$ months) according to DSM-IV criteria (APA, 1994), and 23 typically developing children (12 boys, mean age = 35.0 months) participated in the study. Chronological age (CA), language age (LA) and mental age (MA) for the groups are listed in Table 1. Fifteen of the children with autism were diagnosed at the Child Neuropsychiatry Clinic (Sahlgrenska University Hospital) and four children were diagnosed by another neuropsychiatric team in northern Göteborg. The neuropsychiatric work-up comprised clinically validated instruments, including the Diagnostic Interview for Social and Communication Disorders (DISCO; Wing, Leekam, Libby, Gould, \& Larcombe, 2002), a semi-structured parental interview with excellent interrater and re-test reliability (Billstedt, 2007) or Autism Diagnostic Interview-Revised (ADI-R) (Lord, Rutter, \& Le Couteur, 1994). One child was diagnosed by a paediatrician. In the latter case, the level of autistic behaviour was measured with the Childhood Autism Rating Scale (CARS; Schopler, Reichler, \& Renner Rochen, 1988) in order to validate the diagnosis, and 
the scores indicated mild-moderate autism. The typically developing children were recruited from day-care centres in Göteborg. The children with autism and the typically developing ones were matched for language age at a group level (ns). In addition, there was no significant difference in mental age between the groups.

The children with autism were divided into two groups, a speaking and a non-speaking group, and analysed separately. A child was considered as non-speaking if he/she did not use language for communication during any of the observations. This means that the child could use sounds other than words or simple single words, and still be in the non-speaking group. The definition was made according to the definition of phrase speech used in ADI-R; the spontaneous use of at least two words in combination, one of which must be a verb (Joseph, Tager-Flusberg, \& Lord, 2002). Seven children were considered non-speaking, and 13 children were considered speaking. The categorisation was made by one of the authors (K.S). A researcher not involved in the project categorised the speaking status of five (25\%) randomly selected children and $100 \%$ agreement was obtained. The means of chronological age, mental age and language age of these two groups are presented in Table 1.

[place Table 1 about here]

Estimating language age - Autism. The Peabody Picture Vocabulary Test (PPVT - third edition; Dunn \& Dunn, 1997) and a Swedish version of the MacArthur Communicative Development Inventories (SECDI, Eriksson \& Berglund, 1999; Berglund \& Eriksson, 2000) were administered to all children. Due to the large heterogeneity in the group - language level ranging from non-verbal to well-spoken children - we used the most appropriate test to estimate language age. The test was chosen according to a hierarchic procedure; the PPVT was administered to all children and used to estimate language age when considered reliable 
$(n=9)$. If not, SECDI were administered and used to estimate language age $(n=8)$. In the cases when SECDI was not appropriate to use, the Kaufmann expressive vocabulary subscale (Kaufman \& Kaufman, 1983) was the source for estimating language age ( $\mathrm{n}=3)$.

Estimating language age - Typical development. The PPVT was used to establish language development for 22 of the children with typical development. One child was assessed on the Kaufman because he refused to cooperate on the PPVT.

Estimating mental age-Autism. As part of the clinical assessment the Griffiths II test (Ahlin-Åkerman \& Norberg, 1991; Griffiths, 1970) (n = 9) or the WPPSI (Wechsler, 1999) (n =6) was administered. For four children, the Raven's Coloured Matrices (Raven, 1976) were used. For one child with autism, mental age was not available since the clinical evaluation was missing and he did not cooperate on Raven's matrices.

Estimating mental age - Typical development. The children with typical development were assessed using the McCarthy Scales of Children's Abilities (McCarthy, 1972).

\section{Procedure}

All 43 children came to a laboratory setting at the Department of Psychology, University of Gothenburg, twice, with one or two days between the visits. Each visit lasted approximately $1-1 \frac{1}{2}$ hour and every child was accompanied by at least one parent. Both pretend play and the parents' comments were assessed during a free play situation in a sparsely furnished room with video cameras in two corners; the cameras could be controlled from a different room.

\section{Measures}

Deferred imitation. Deferred imitation was measured by actions on objects. The objects were replicas of the ones originally used by Meltzoff $(1985 ; 1988)$. The first object was two wooden rectangles connected with a hinge and the action was to fold them together by using the elbow. The second object was a black box with a hidden black button on top and the 
action was to press the button with a pencil, which produced a beeping sound. The third object was a plastic egg that produced a rattling sound when shaken, and the action was to shake the egg. The fourth object was a collapsible cup that could be folded up like a telescope by pressing downward on it, which was the target action. The fifth object consisted of two items, one empty plastic cup and a string of beads, and the action was to pick up the beads and lower them into the plastic cup.

The objects were manipulated by an experimenter without letting the child touch or play with the objects to ensure that no motoric experience was created. After a delay of 2 or 3 days $(\mathrm{M}($ hours $)=51.09, \mathrm{SD}=9.06)$ the child was offered an opportunity to imitate the target action. The response time allowed was 20 seconds after the child touched the object.

Two of the authors (K.S. and M.H.) coded the responses on all deferred imitation tasks. The observer agreement was assessed by Cohen's kappa $(\kappa=.89)$.

Pretend play. The child and one parent took part in a play procedure adapted from research by Bloom (e.g. Bloom \& Tinker, 2001). The play session was 24 minutes long and the experimenter interrupted the play twice (after 8 minutes and after 16 minutes) by entering the room with additional toys. The objects were a standard set of toys including cars and garage, toy animals, a doll and a teddy bear, a toy set, a small doll family, large wooden beads on a string, a ramp for cars and a small slide. Eleven single, or sets, of toys were used. The whole session was videotaped, but only the last 8 minutes were coded. To ensure that this session was not affected by being the last one, the parent and child were not aware of how long the play session would continue or how many interruptions there would be. Pretend play was defined as either object substitution (e.g. using a block as a car), adding a pretend property to a toy (e.g. the doll is hungry), pretending that something exists when it does not (e.g. there is a lion behind the curtain) or role playing (e.g. the child pretends to be the mother) (Leslie, 1987). In the present study, both a dichotomous measure of pretend play 
(yes/no) and the duration of pretend play is used. Every time the child pretended spontaneously according to the criteria, the duration was coded. A graduate student coded all play situations for duration of pretend play. One of the authors (K.S.) coded 6 of the 43 children, selected on a random basis, and the agreement of duration was assessed by Cohen's kappa $(\kappa=.85)$.

Parents' comments. The parents' verbal comments about objects or actions with objects during the free play were coded as one out of two categories, depending on the child's focus of attention. Comments about an object outside the child's focus of attention (unsynchronized comments) were coded using 5-second time samples and comments about an object within the child's focus of attention (synchronized comments) were coded using 10-second time samples. A behavior was only noted once during an interval, even if it occurred several times. The synchronized comments were more like coherent talk with longer sentences and not as distinct and short as the unsynchronized comments. It was more difficult to obtain acceptable agreement between coders for the synchronized comments using a 5 second time sample. Thus, the difference in sampling units depended on reliability issues. In the analysis the frequencies were adjusted in order to represent equal number of time units per minute.

As an example, "This doll has a nice dress" would be coded as a synchronized comment if the child looked at and/or held the doll, and as an unsynchronized comment if the child did not have his or her attention on the doll. Three parent-child dyads (one in the autism group and two in the typical group) were excluded because the parents spoke a language unknown to the coder. A graduate student coded the free play for both synchronized and unsynchronized comments. One of the authors (K.S.) coded 6 of the 40 children, selected on a random basis, and the agreement was assessed by Cohen's kappa $(\kappa=.76)$ for both categories. 


\section{Statistical Analysis}

Non-parametric tests were used in all analyses due to skewness. Mann-Whitney U test, Wilcoxon signed ranks test and chi square test were used for group comparisons. Correlations between variables were computed with Spearman's correlation coefficient. Even if specific hypotheses were formulated, a two-tailed significant level (alpha $<.05)$ was used due to conservative reasons since the sample size was small.

\section{Ethics}

The study was approved by the ethical committee at University of Gothenburg (Ö 55502).

$$
\text { Results }
$$

\section{Pretend Play}

There was a significant association between group of children and pretend play $\chi^{2}(1, N$ $=43)=3.74, p<.05$. Nine children with autism showed pretend play during free play with their parents, 11 children with autism did not show pretend play. For the children with typical development, 17 showed pretend play and 6 did not (Table 2).

The same analysis was conducted comparing non-speaking children with autism and speaking children with autism with the group of typically developing children. A significant association $\left(\chi^{2}(1, \mathrm{~N}=30)=7.95, p<.01\right)$ was yielded in the comparison between nonspeaking children with autism and children with typical development. One non-speaking child with autism showed pretend play and 6 non-speaking children did not (Table 2). No significant association was found between speaking children with autism and children with typical development. 


\section{Deferred Imitation}

Deferred imitation was significantly less present in the group of children with autism compared to the typical group $(U=345.5, p<.01$, Table 3$)$. However, four of the children with autism solved almost all deferred imitation tasks (a score of 4 or 5). Both non-speaking and speaking children with autism showed lower scores on deferred imitation compared to the typical group $(U=138.5, p<.01$ and $U=207, p<.05$, respectively).

$$
\text { [place Table } 3 \text { about here] }
$$

\section{Parents Comments}

Overall, parents of children with autism and parents of the typically developing group yielded more synchronized than unsynchronized comments. However, parents of children with autism used significantly fewer synchronized comments compared to parents of children with typical development $(U=277, p<.05$, Table 3$)$. Parents' unsynchronized comments did not differ between the groups (Table 3).

Comparing the parents of non-speaking children with autism and parents of typical children revealed a difference in synchronized comments between the groups $(U=121.5, p<$ .05). Parents of non-speaking children with autism used fewer synchronized comments compared to parents of typical children (Table 3). No significant difference was found between parents' use of synchronized comments between the speaking autism group and the typical group (Table 3). 
No differences in unsynchronized comments were found between parents of the nonspeaking children with autism or the speaking children with autism compared to parents of the typical children.

Synchronized comments were significantly more frequent than unsynchronized comments for both speaking children with autism $(T=2, p<.01)$ and typically developing children $(T=1, p<.001)$. No significant difference between parents use of synchronized and unsynchronized comments were found for the non-speaking children with autism.

\section{Correlations}

In order to investigate if deferred imitation, pretend play, and parents' comments were related, correlations were computed (Table 4).

[place Table 4 about here]

For children with autism, a negative correlation was found between deferred imitation and parents' unsynchronized comments $\left(\mathrm{r}_{\mathrm{s}}=-.53, p<.05\right)$ i.e. parents of children with a high score on deferred imitation used unsynchronized comment to a lesser degree. For the children with typical development, a positive correlation was found between deferred imitation and parents' unsynchronized comments $\left(\mathrm{r}_{\mathrm{s}}=.50, p<.05\right)$.

For children with autism, a positive correlation was found between deferred imitation and mental age $\left(\mathrm{r}_{\mathrm{s}}=.53, p<.05\right)$. A positive correlation between language age and mental age was found for both children with autism $\left(\mathrm{r}_{\mathrm{s}}=.69, p<.05\right)$ and children with typical development $\left(\mathrm{r}_{\mathrm{s}}=.60, p<.05\right)$.

For the children with typical development, positive correlations were found between pretend play and LA and MA, ( $\mathrm{r}_{\mathrm{s}}=.49$ and .50 respectively). 
Deferred imitation and MA correlated positively in the speaking autism group $\left(\mathrm{r}_{\mathrm{s}}=.71\right.$, $p<.01)$. No significant correlations were found in the non-speaking autism group.

\section{Discussion}

The present study showed that both pretend play and deferred imitation were reduced among children with autism compared to children with typical development. Deferred imitation was reduced both among speaking and non-speaking children with autism while pretend play was less evident among the non-speaking children with autism. In addition, deferred imitation was negatively correlated to the parents' use of unsynchronized comments in the autism group and positive correlated in the typical group.

\section{Pretend Play}

Pretend play was significantly less common among children with autism in comparison to typically developing children, thus replicating the findings of previous studies (see Jarrold, 2003 for a review). However, doing separate analysis with non-speaking and speaking children with autism revealed that only the non-speaking children with autism showed reduced pretend play. Only one child in the non-speaking autism group showed pretend play, while in the speaking autism group eight children showed pretend play. Of the nine children with autism that did spend time in pretend play, two children (in the speaking autism group) spent more than $25 \%$ of the whole play period in pretend play (including role play initiated by the boys). A closer look at these two children revealed that their estimated language age was lower than their developmental level $(\mathrm{MA}=60$ and $55 \mathrm{~m}, \mathrm{LA}=35 \mathrm{~m}$ for both $)$ and close to the mean for the children with autism in this study and, more striking, they performed high on deferred imitation. One boy scored five out of five and the other boy scored four out of five. Furthermore, their parents used very few unsynchronised comments (three and zero). Although children with autism often show a lower frequency of pretend play when compared to other groups (Jarrold, 2003), individual children with autism sometimes show spontaneous 
pretend play (e.g. Libby, Powell, Messer, \& Jordan, 1998) and in some cases, even group differences are absent (Morgan, Maybery \& Durkin, 2003), which was the case for the comparison between speaking children with autism and typically developing children, in the present study. These results speak against the notion of a global pretend play deficit in autism.

\section{Deferred imitation}

Deferred imitation was reduced among both speaking and non-speaking children with autism in comparison to typically developing children. This was expected and is in line with results from previous studies (Dawson, et al., 1998, Rogers et al., 2008). The present study also reveals that difficulties with deferred imitation probably do not depend on language capacity, since both non-speaking and speaking children with autism showed reduced performance. Similar findings were seen in the study by Toth et al. (2007) in which deferred imitation had low correlations with language ability when measured concurrently in 3-4 year old children with autism. Performance on deferred imitation tasks require recall memory ability and have been extensively used as a memory test in typically developing infants, but performance also relies on the ability and motivation to imitate. When using deferred imitation in children with autism it is possible that the imitation demands of the test mask the child's memory ability since children with autism are described as having an imitation deficit (e.g. Rogers \& Pennington, 1991). Comparing deferred imitation with other tests of both memory and imitation ability is needed before firm conclusions can be drawn about the true capacity of deferred imitation in this group.

\section{Parents' comments}

The current study shows that parents use of synchronized comments depends on whether their child has autism or not, and if their child uses spoken language or not. Parents of children with autism used fewer synchronized comments compared to parents of typically developing children. The difference in synchronized, but not unsynchronized comments 
between parents of children with autism and parents of children with typical development contrasts with the results reported by Watson (1998). She found that parents of children with autism used the same amount of child-focused (synchronized) verbalizations but more out-offocus (unsynchronized) verbalizations, as compared to parents of typically developing children. Only parents of speaking children with autism used the same amount of synchronized comments as parents of typically developing children. In Watson's study, the participants had a lower language age $(M=20$ months for both groups $)$ as compared to the children in the present study, a difference that could explain the divergent results on unsynchronized comments. In our sample, the non-speaking autism group is more comparable to Watson's sample. The parents of this group used more unsynchronized comments compared to the parents of typical children, although the difference did not reach statistical significance $(p=.07)$. It is possible that the small sample size prevents us from discovering group differences, and research with larger groups might be better at finding qualitative differences in the interaction patterns between parents of children with or without autism as well as non-speaking and speaking children.

The amount of synchronized and unsynchronized comments did not differ for the nonspeaking children with autism, which indicates a qualitatively different interaction for these parent-child dyads. It is possible that non-speaking children with autism are less interested in interaction, and that this more or less forces the parent to adjust her/his interaction style to be more directive in order to create situations of mutual interest. During the observation, many parents of less socially interested children with autism worked very hard trying to get the child to play with them. They picked up toys they thought could interest the child and started to play on their own while calling the child's attention (e.g. "Look what fun this is, the cars are driving down the slide!"). When the child did not respond, the parent usually tried 
something else, which naturally resulted in an increased use of unsynchronized comments and a decreased use of synchronized comments.

\section{Correlations}

No relation was found between deferred imitation and pretend play in the autism group or in the typically developing group. This was unexpected and in contrast to previous research on typically developing children (Nielsen \& Dissanayake, 2004). One might speculate that the low imitation demands in the deferred imitation task (simple motor imitation) does not demonstrate a challenge for typical children of this age-group, resulting in a ceiling effect in imitation performance. Why no difference was found in the autism group, even though both areas were affected in this group, might be due to the low variability in the pretend play variable. A different measure of pretend play might be better at capturing differences in pretend play performance and a possible association with deferred imitation.

Deferred imitation had a negative relation to parents' use of unsynchronized comments in the autism group. This suggests that the child's ability to use imitation is affected by the interaction style of the parent. It might be the same parents that use few directives in play also encourage imitation in everyday interaction. But it might also be that children who are motivated to imitate are the socially interested children whose parents does not need to use a directive interaction style in order create mutual play situations. It is notable that the opposite relation is found in the typical group; a positive correlation between deferred imitation and parents' use of unsynchronized comments. We have no plausible explanation to this result but it could be that the same interaction style has completely different meanings for different parent-child dyads.

\section{Limitations}

A couple of limitations of the present study need to be pointed out. First, the groups were not matched on gender. However, additional comparisons comprising only boys with 
autism and boys with typical development yielded no differences from the results based on both genders. This suggests that the differences between children with autism and those with typical development reported in the present study did not depend on gender. Second, the small sample size made variation in performance difficult to detect. Future studies would also benefit from matched groups at an individual level (in the present study they were matched at a group level according to language age).

\section{Conclusion}

The present study showed that pretend play and deferred imitation was reduced among children with autism compared to children with typical development. For deferred imitation, both non-speaking and speaking children with autism showed reduced performance, while for pretend play this was only seen in the non-speaking group. This speaks against a global pretend play deficit for children with autism and highlights the importance of deferred imitation. Deferred imitation was also related to parent interaction style, although different relations were found for children with autism and children with typical development. The present study also suggests that parents' comments during play differed if their child had a diagnosis or not. Parents of non-speaking children with autism especially seem to differ in their verbal comments during play compared to the other parents. 


\section{References}

Ahlin-Åkerman, B., \& Norberg, L. (1991). Griffiths utvecklingsskalor. Göteborg: Psykologiförlaget.

APA. (1994). American Psychiatry Association. Diagnostic and statistical manual (4th ed.). Washington, DC: APA Press.

Berglund, E., \& Eriksson, M. (2000). Communicative development in Swedish children 16-28 months old: the Swedish early communicative development inventory - words and sentences. Scandinavian Journal of Psychology, 41(2), 133-144.

Barr, R., Dowden, A., \& Hayne, H. (1996). Developmental changes in deferred imitation by 6- to 24-month-old infants. Infant Behavior and Development, 19(2), 159-170.

Billstedt, E. (2007). Use of the DISCO (Diagnostic Interview for Social and Communication Disorders) in population cohorts. Doctoral dissertation. Göteborg University: Institute of Neuroscience and Physiology, Child and Adolescent Psychiatry.

Bloom, L., \& Tinker, E. (2001). The intentionality model and language acquisition. Monographs of the Society for Research in Child Development, 66(4).

Charman, T., \& Baron-Cohen, S. (1997). Brief report: prompted pretend play in autism. Journal of Autism and Developmental Disorders, 27(3), 325-332.

Dawson, G., Meltzoff, A. N., Osterling, J., \& Rinaldi, J. (1998). Neuropsychological correlates of early symptoms of autism. Child Development, 69(5), 1276-1285.

Dunn, L. M., \& Dunn, L. M. (1997). Peabody Picture Vocabulary Test: Third Edition. Circle Pines, MN: American Guidance Service.

Eheart, B. (1982). Mother-child interactions with nonretarded and mentally retarded preschoolers. American Journal of Mental Deficiency, 87(1), 20-25.

Eriksson, M., \& Berglund, E. (1999). Swedish Early Communicative Development Inventory - words and gestures. First Language, 19(55), 55-90. 
Gillberg, C. (1991). Outcome in autism and autistic-like conditions. Journal of the American Academy of Child \& Adolescent Psychiatry, 30, 375-382.

Green, J., Charman, T., McConachie, H., Aldred, C., Slonims, V., Howlin, P., LeCouteur, A., Leadbitter, K., Hudrey, K., Byford, S., Barrett, B., Temple, K., Macdonald, W., \& Pickles, A. (2010). Parent-mediated communication-focused treatment in children with autism (PACT): a randomised controlled trial. Lancet, 375, 2152-2160.

Griffiths, R. (1970). The Abilities of Young Children. A Study in Mental Measurement. London: University of London Press.

Harris, P. L. (1989). Children and emotion. Oxford: Blackwell.

Hedenbro, M., \& Tjus, T. (2007). A case study of parent-child interactions of a child with autism spectrum disorder (3-48 months) and comparison with typically developing peers. Child Language Teaching and Therapy, 23(2), 201-222.

Heimann, M., Strid, K., Smith, L., Tjus, T., Ulvund, S. E., \& Meltzoff, A. N. (2006). Exploring the relation between memory, gestural communication, and the emergence of language in infancy: A longitudinal study. Infant and Child Development, 15(3), 233-249.

Jarrold, C. (2003). A review of research into pretend play in autism. Autism, 7(4), 379-390.

Joseph, R. M., Tager-Flusberg, H., \& Lord, C. (2002). Cognitive profiles and social communicative functioning in children with autism spectrum disorder. Journal of Child Psychology and Psychiatry 43(6), 807-820.

Kasari, C., Sigman, M., Mundy, P., Yirmiya, N. (1988). Caregiver interactions with autistic children. Journal of Abnormal Child Psychology, 16, 45-56.

Kaufman, A. S., \& Kaufman, N. L. (1983). Kaufman assessment battery for children. Circle Pines, Minnesota: American Guidance Service. 
Konstantareas, M. M., Zajdeman, H., Homatidis, S., \& McCabe, A. (1988). Maternal speech to verbal and higher functioning versus nonverbal and lower functioning autistic children. Journal of Autism and Developmental Disorders, 18(4), 647-656.

Leslie, A. M. (1987). Pretense and representation: the origins of "theory of mind". Psychological Review, 94(4), 412-426.

Libby, S., Powell, S., Messer, D., \& Jordan, R. (1998). Spontaneous play in children with autism: a reappraisal. Journal of Autism and Developmental Disorders, 28(6), 487 497.

Lord, C., Rutter, M., \& Le Couteur, A. (1994). Autism diagnostic interview-revised: a revised version of a diagnostic interview for caregivers of individuals with possible pervasive developmental disorders. Journal of Autism and Developmental Disorders, 24(5), 659686.

McCarthy, D. (1972). McCarthy Scales of Children's Abilities. New York: The Psychological Corporation/Harcourt Brace Jovanovich.

McEwen, F., Happé, F., Bolton, P., Rijsdijk, F., Ronald, A., Dworzynski, K., \& Plomin, R. (2007). Origins of individual differences in imitation: links with language, pretend play, and socially insightful behaviour in two-year-old twins. Child Development, $78(2), 474-492$.

Meltzoff, A. N. (1985). Immediate and deferred imitation in fourteen- and twenty-fourmonth-old infants. Child Development, 56(1), 62-72.

Meltzoff, A. N. (1988). Infant imitation and memory: nine-month-olds in immediate and deferred tests. Child Development, 59(1), 217-225.

Meltzoff, A. N. (2004). The case for developmental cognitive science: theories of people and things. In G. Bremner \& A. Slater (Eds.), Theories of infant development (pp. 145173). Oxford: Blackwell Publishing. 
Morgan, B., Maybery, M. \& Durkin, K. (2003). Weak central coherence, poor joint attention, and low verbal ability: independent deficits in early autism. Developmental Psychology, 39(4), 646-656.

Munson, J., Faja, S., Meltzoff, A., Abbott R. \& Dawson, G. (2008). Neurocognitive predictors of social and communicative developmental trajectories in preschoolers with autism spectrum disorders. Journal of the International Neuropsychological Society, 14, 956966.

Nielsen, M., \& Dissanayake, C. (2004). Pretend play, mirror self-recognition and imitation: a longitudinal investigation through the second year. Infant Behavior and Development, $27,342-365$.

Noll, L. M., \& Harding, C. G. (2003). The relationship of mother-child interaction and the child's development of symbolic play. Infant Mental Health Journal, 24(6), 557-570.

Raven, J. C. (1976). Coloured progressive matrices. Oxford: Oxford Psychologists Press Ltd.

Rogers, S. J. \& Pennington, B. F. (1991). A theoretical approach to the deficits in infantile autism. Development and Psychopathology, 3, 137-162.

Rogers, S. J., Young, G. S., Cook, I., Giolzetti, A. \& Ozonoff, S. (2008). Deferred and immediate imitation in regressive and early onset autism. Journal of Child Psychology and Psychiatry, 49(4), 449-457

Schopler, E., Reichler, R. J., \& Renner Rochen, B. (1988). The childhood autism rating scale. Los Angeles, CA: Western Psychological Services.

Siller, M., \& Sigman, M. (2002). The behaviors of parents of children with autism predict the subsequent development of their children's communication. Journal of Autism and Developmental Disorders, 32(2), 77-89. 
Siller, M., \& Sigman, M. (2008). Modeling longitudinal change in the language abilities of children with autism: parent behaviors and child characteristics as predictors to change. Developmental Psychology, 44(6), 1691-1704.

Slade, A. (1987). A longitudinal study of maternal involvement and symbolic play during the toddler period. Child Development, 58, 367-375.

Striano, T., Tomasello, M., \& Rochat, P. (2001) Social and object support for early symbolic play. Developmental Science, 4(4), 442-455.

Strid, K., Heimann, M., Smith, L., Gillberg, C., \& Tjus, T. (submitted). Deferred imitation and social communication in speaking and non-speaking children with autism.

Strid, K., Tjus, T., Smith, L., Meltzoff, A. N., \& Heimann, M. (2006). Infant recall memory and communication predicts later cognitive development. Infant Behavior and Development, 29(4), 545-553.

Tjus, T., Heimann, M., \& Nelson, K.E. (2001). Interaction patterns between children and their teachers when using a specific multi-media and communication strategy. Autism, 5 (2), 175-187.

Tomasello, M., \& Farrar, M. J. (1986). Joint attention and early language. Child Development, 57(6), 1454-1463.

Toth, K., Munson, J., Meltzoff, A. N., \& Dawson, G. (2006). Early predictors of communication development in young children with autism spectrum disorder: Joint attention, imitation, and toy play. Journal of Autism and Developmental Disorders, 36(8), 993-1005.

Watson, L. R. (1998). Following the child's lead: mothers' interactions with children with autism. Journal of Autism and Developmental Disorders, 28(1), 51-59.

Waxman, S.R. (2002). Early word learning and conceptual development: Everything had a name, and each name gave birth to a new thought. In U. Goswami (Ed.), Blackwell 
Handbook of Childhood Cognitive Development (pp. 102-126). Oxford: Blackwell Publishing.

Wechsler, D. (1999). Wechsler pre-school and primary scale of intelligence - revised. Swedish version. Stockholm: Psykologiförlaget.

Wing, L. (1997). Syndromes of autism and atypical development. In D. J. Cohen \& F. R. Volkmar (Eds.), Handbook of autism and pervasive developmental disorders (pp. 148170). New York: Wiley.

Wing, L., Leekam, S. R., Libby, S. J., Gould, J., \& Larcombe, M. (2002). The diagnostic interview for social and communication disorders: background, inter-rater reliability and clinical use. Journal of Child Psychology and Psychiatry and Allied Disciplines, 43(3), 307-325. 
Author Note

Karin Strid and Tomas Tjus, University of Gothenburg, Department of Psychology, Göteborg, Sweden. Mikael Heimann, Linköping University, Department of Behavioural Sciences, Linköping, Sweden and Swedish Institute of Disability Research. Support for this research was provided by research grants from the Swedish Council for Working Life and Social Research, Stockholm, Sweden to Mikael Heimann (grant \# 2001-1113), Erland Hjelmquist (grant \# 2005-1700) and to Tomas Tjus (grant \# 2008-0518). The work of Mikael Heimann was also supported by the ESF COST Action BM 1004 Enhancing the Scientific Study of Early Autism (ESSEA). Preliminary versions of data presented in this article have been presented at the Meeting of Minds in Herning, Denmark, February, 2007. The authors wish to thank Katarina Nilheim for generous assistance in completing this study, and Karolina Haglund and Kari Reckebo for data preparation, as well as the parents and children who participated.

Correspondence concerning this article should be addressed to: Karin Strid, Department of Psychology, University of Gothenburg, Box 500, SE-405 30 Göteborg, Sweden. Phone: +46 31 7864284; Fax: +46 31 7864628; email: karin.strid@psy.gu.se 
Table 1.

Chronological age, language age and mental age (M and SD) for the children with autism and the typical children and for the non-speaking and speaking subgroups among the children with autism. Group comparisons with Mann-Whitney U test.

\begin{tabular}{|c|c|c|c|c|}
\hline & \multicolumn{2}{|c|}{ Total group } & \multicolumn{2}{|c|}{ Autism group } \\
\hline & $\begin{array}{l}\text { Autism } \\
(\mathrm{N}=20)\end{array}$ & $\begin{array}{l}\text { Typical } \\
(\mathrm{N}=23)\end{array}$ & $\begin{array}{l}\text { Non-speaking } \\
\qquad(\mathrm{n}=7)\end{array}$ & $\begin{array}{l}\text { Speaking } \\
(\mathrm{n}=13)\end{array}$ \\
\hline Chronological age & $66.8(17.32)$ & $34.7(5.20)^{*}$ & $59.4(19.70)^{* 1}$ & $70.8(15.24)^{* 1}$ \\
\hline Language age & 29.7 (15.99) & $35.0(13.15)$ & $13.6(1.62) * 1$ & $38.3(13.11)$ \\
\hline Mental age & $45.2(19.36) \mathfrak{a}$ & $37.0(8.95)$ & $24.7(8.31) *^{10 \alpha}$ & $54.7(15.0)^{* 1}$ \\
\hline \multicolumn{4}{|c|}{${ }^{1}$ compared to the typical group } & \\
\hline \multicolumn{5}{|l|}{ a 19 due to data loss } \\
\hline 6 due to data loss & & & & \\
\hline
\end{tabular}


Table 2.

Number of children showing pretend play in the autism group (total, non-speaking and speaking) and the typical group.

Autism Typical

\begin{tabular}{lcccc}
\hline & All & Non-Speaking & Speaking & \\
\hline Pretend Play & 9 & 1 & 8 & 17 \\
No pretend play & 11 & 6 & 5 & 6 \\
\hline \hline
\end{tabular}


Table 3.

Means (SD) on deferred imitation, pretend play, and parents' type of comments for children with autism and children with typical development.

\begin{tabular}{|c|c|c|c|c|c|c|c|}
\hline & \multicolumn{2}{|l|}{ Typical (T) } & \multicolumn{2}{|l|}{ Autism (A) } & \multirow[b]{2}{*}{$\mathrm{T}$ vs $\mathrm{A}^{2}$} & \multirow[b]{2}{*}{$\mathrm{T}$ vs $(\mathrm{A}) \mathrm{NS}^{2}$} & \multirow[b]{2}{*}{$\mathrm{T}$ vs $(\mathrm{A}) \mathrm{S}^{2}$} \\
\hline & & All & Non-Speaking (NS) & Speaking (S) & & & \\
\hline & & $(n=20)$ & $(n=7)$ & $(n=13)$ & $p$ & $p$ & $p$ \\
\hline Deferred imitation (freq) & $3.74(.86)$ & $2.80(1.01)$ & $2.29(.95)$ & $3.08(.95)$ & $<.01$ & $<.01$ & $<.05$ \\
\hline Synchronized (freq) ${ }^{3}$ & $17.67(6.09)$ & $13.16(5.95)$ & $10.14(5.82)$ & $14.92(5.50)$ & $<.05$ & $<.05$ & $\mathrm{~ns}$ \\
\hline Unsynchronized (freq) $)^{3}$ & $2.45(1.72)$ & $3.16(2.10)$ & $4.21(2.14)$ & $2.54(1.89)$ & ns & ns & ns \\
\hline
\end{tabular}

\footnotetext{
${ }^{1} \mathrm{NS}=$ non-speaking $\mathrm{S}=$ speaking

${ }^{2}$ Group comparisons with Mann-Whitney

${ }^{3} \mathrm{n}=19$ (autism group) and $\mathrm{n}=21$ (typical group)
} 
Table 4.

Correlations (Spearman) between duration of pretend play, frequency of parents' comments, joint attention, deferred imitation, language age and mental age for children with autism and children with typical development.

\begin{tabular}{|c|c|c|c|c|c|}
\hline & $\overline{\mathrm{DI}}$ & Pretend play & Synchronized & Unsynchronized & LA \\
\hline \multicolumn{6}{|l|}{ Autism } \\
\hline Deferred imitation & ----- & & & & \\
\hline Pretend play & .24 & ----- & & & \\
\hline Synchronized comments & .26 & .18 & ----- & & \\
\hline Unsynchronized comments & $-.53^{*}$ & -.29 & -.29 & ---- & \\
\hline Language age & .10 & .45 & .10 & -.35 & ---- \\
\hline \multirow[t]{2}{*}{ Mental age } & $.53^{*}$ & .41 & .28 & -.28 & $.69 *$ \\
\hline & DI & Pretend play & Synchronized & Unsynchronized & LA \\
\hline \multicolumn{6}{|c|}{ 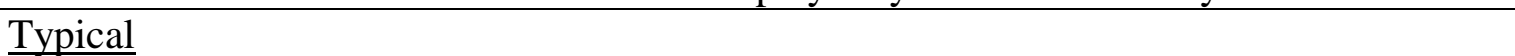 } \\
\hline$\overline{\text { Deferred imitation }}$ & ----- & & & & \\
\hline Pretend play & .09 & ----- & & & \\
\hline Synchronized comments & -.14 & -.02 & ----- & & \\
\hline Unsynchronized comments & $.50 *$ & -.20 & .28 & ---- & \\
\hline Language age & .13 & $.49 *$ & -.16 & -.18 & ---- \\
\hline Mental age & -.20 & $.50 *$ & -.14 & -.30 & $.60 *$ \\
\hline
\end{tabular}

